\title{
Socioeconomic inequalities in newborn care during facility and home deliveries: a cross sectional analysis of data from demographic surveillance sites in rural Bangladesh, India and Nepal
}

\author{
Erik de Jonge ${ }^{1^{*}}$ (D) Kishwar Azad², Munir Hossen², Abdul Kuddus², Dharma S. Manandhar ${ }^{3}$, Ellen van de Poel $^{5}$, \\ Swati Sarbani Roy ${ }^{4}$, Naomi Saville ${ }^{6}$, Aman Sen ${ }^{3}$, Catherine Sikorski ${ }^{6}$ Prasanta Tripathy ${ }^{4}$, Anthony Costello ${ }^{6}$ \\ and Tanja A. J. Houweling ${ }^{1,6}$
}

\begin{abstract}
Background: In Bangladesh, India and Nepal, neonatal outcomes of poor infants are considerably worse than those of better-off infants. Understanding how these inequalities vary by country and place of delivery (home or facility) will allow targeting of interventions to those who need them most. We describe socio-economic inequalities in newborn care in rural areas of Bangladesh, Nepal and India for all deliveries and by place of delivery.

Methods: We used data from surveillance sites in Bangladesh, India and from Makwanpur and Dhanusha districts in Nepal, covering periods from 2001 to 2011. We used literacy (ability to read a short text) as indicator of socioeconomic status. We developed a composite score of nine newborn care practices (score range 0-9 indicating infants received no newborn care to all nine newborn care practices). We modeled the effect of literacy and place of delivery on the newborn care score and on individual practices.

Results: In all study sites (60,078 deliveries in total), use of facility delivery was higher among literate mothers. In all sites, inequalities in newborn care were observed: the difference in new born care between literate and illiterate ranged $0.35-0.80$. The effect of literacy on the newborn care score reduced after adjusting for place of delivery (range score difference literate-illiterate: $0.21-0.43$ ).

Conclusion: Socioeconomic inequalities in facility care greatly contribute to inequalities in newborn care. Improving newborn care during home deliveries and improving access to facility care are a priority for addressing inequalities in newborn care and newborn mortality.
\end{abstract}

\section{Background}

Neonatal mortality in Bangladesh, India and Nepal is high and socioeconomic inequalities in neonatal outcomes are substantial $[1,2]$. Although there is agreement about the interventions that would save most newborn lives, $[3,4]$ there are considerable socioeconomic inequalities in coverage of such newborn care interventions $[5,6]$.

\footnotetext{
* Correspondence: h.c.c.dejonge@erasmusmc.nl

1 Department of Public Health, Erasmus University Medical Center, P.O. Box 2040, 3000, CA, Rotterdam, the Netherlands

Full list of author information is available at the end of the article
}

Whether newborn care interventions should be delivered at home or in the facility is an important question, both in terms of quality of care and from an equity point of view. Newborn care is much better when a delivery takes place in a health facility, [7] but use of health facility delivery is highly unequal [8]. To what extent can inequalities in newborn care be explained by place of delivery?

Much of the research on inequalities in reproductive, maternal, newborn and child care relies on the Demographic Health Surveys (DHS) [9]. The DHSs are

(c) The Author(s). 2018 Open Access This article is distributed under the terms of the Creative Commons Attribution 4.0 International License (http://creativecommons.org/licenses/by/4.0/), which permits unrestricted use, distribution, and 
nationally-representative household surveys that provide data for monitoring indicators in population, health, and nutrition. Funded by USAID and other donors, the DHS surveys are carried out in more than 90 developing countries. Bangladesh has implemented six surveys since 1993, Nepal six surveys since 1987 and India three surveys since 1992. In 2007 the DHS in Bangladesh began to collect data on newborn care with questions on the use of clean instruments to cut the umbilical cord, cord care, bathing delays and prevention of hypothermia [10]. In 2011, the DHS in Nepal began to collect similar data on newborn care, underscoring the importance of measuring improvements in newborn care practices to improve neonatal survival [11]. However, the data on newborn care were only collected for women giving birth at home, which makes it impossible to compare home and facility deliveries. Furthermore, the DHS newborn care questions were asked to women who gave birth up to three years ago, which may result in recall bias.

In this paper we describe and compare socio-economic inequalities in newborn care by place of delivery using data from four demographic surveillance sites in rural areas of Bangladesh, Nepal and India in order to guide policies for reducing inequalities in coverage of these practices and in neonatal mortality.

\section{Methods}

\section{Study population}

We analyzed data from demographic surveillance sites, located in Jharkhand and Odisha state in India $(n=8720)$, Dhanusha district $(n=17,835)$ and Makwanpur district $(n$ $=6688$ ) in Nepal and Bogra, Faridpur and Moulvibazar districts in Bangladesh $(n=26,835)$. The surveillance sites were developed for cluster-randomized trials of a community intervention to reduce maternal and neonatal mortality. Table 1 provides details on the sites. In this study, we analyzed data from the control arm of the trials, because the intervention is known to have affected newborn care practices [12]. We included all live born infants. If a mother delivered twins or triplets, we only included the infant born first.

\section{Data collection}

Surveillance of all births, neonatal and maternal deaths in the study areas was done by key informants. Key informants were usually traditional birth attendants in Bangladesh and incentivized 'enumerators' in Nepal and India, recruited to cover approximately 250 households each. The key informant notified a salaried interviewer when a mother delivered or when a death occurred. The interviewer would then visit the mother at home to conduct a structured interview around 6 weeks after delivery. The interview addressed the outcome of the pregnancy, home care practices and health care-seeking during pregnancy, delivery and the neonatal period, as well as socioeconomic and demographic information like educational attainment and household assets. Data were collected on paper, checked by auditors, entered by separate data entry operators, and cross-checked by data managers for data quality purposes.

\section{Outcomes: Newborn care practices}

In order to compare newborn care at home and in health facilities, we selected a set of newborn care practices that should be performed during or after any delivery, both at home and in the facility, following guidance from the WHO on essential newborn care (Table 2) [13].

In order to summarize newborn care practices for the analysis, a score was calculated by summing these indicators. All indicators were coded as 1 if a practice was

Table 1 Brief descriptions of the demographic surveillance sites

\begin{tabular}{|c|c|c|c|c|}
\hline & Bangladesh & India & Nepal (Makwanpur) & Nepal (Dhanusha) \\
\hline Location & $\begin{array}{l}\text { Bogra, } \\
\text { Maulvibazaar } \\
\text { and Faridpur } \\
\text { districts }\end{array}$ & $\begin{array}{l}\text { West Singhbhum and Saraikela } \\
\text { Districts (Jharkhand); Keonjhar } \\
\text { Districts (Odisha) }\end{array}$ & $\begin{array}{l}\text { Makwanpur district, } \\
\text { central region mid-hills }\end{array}$ & $\begin{array}{l}\text { Dhanusha district, } \\
\text { central plains of Nepa }\end{array}$ \\
\hline Period & $\begin{array}{l}\text { February 1st } \\
2005-31 \\
\text { December } \\
2009\end{array}$ & 1st July 2005 - 30th June 2008 & $\begin{array}{l}\text { 1st November } 2001-31 \text { st } \\
\text { October } 2004 \text { (phase 1)1st } \\
\text { November } 2004-31 \text { st } \\
\text { October } 2008 \text { (phase 2) }\end{array}$ & $\begin{array}{l}\text { 1st September } 2006 \text { - } \\
\text { 13th April } 2011\end{array}$ \\
\hline $\begin{array}{l}\text { Number of clusters } \\
\text { (number included } \\
\text { in the study) }\end{array}$ & 18(9) & $36(18)$ & $\begin{array}{l}\text { 24(12) (Phase 1) } \\
30(6) \text { (Phase } 2 \text {-former control } \\
\text { clusters became intervention } \\
\text { clusters and } 6 \text { new control } \\
\text { clusters recruited) }\end{array}$ & $60(30)$ \\
\hline $\begin{array}{l}\text { Annual births sampled } \\
\text { per cluster (number } \\
\text { included in the study) }\end{array}$ & $596(119)$ & $171(38)$ & 115(70) & 104(17) \\
\hline $\begin{array}{l}\text { Approximate cluster } \\
\text { population }\end{array}$ & 28,000 & 6400 & 4000 & 8000 \\
\hline
\end{tabular}


Table 2 Newborn care practices included in the essential newborn care score for each study site

\begin{tabular}{|c|c|}
\hline Hand washing & Birth attendant washed hands before delivery \\
\hline Clean delivery kit & $\begin{array}{l}\text { A clean delivery kit (CDK) was used during the delivery. A CDK usually contains a small bar of soap for washing hands, } \\
\text { a plastic sheet to serve as the delivery surface, clean string for tying the umbilical cord, a new razor blade for cutting } \\
\text { the cord, and pictorial instructions that illustrate the sequence of delivery events and hand-washing. }\end{array}$ \\
\hline Clean instrument & The umbilical cord was cut with a sterilized instrument (new or boiled razor blade, surgical blade or scissors). \\
\hline Appropriate cord care & After cutting the cord either dry cord care was practised or an antiseptic was applied to the stump. \\
\hline Wrapped within 5 mins & The baby was wrapped in clean cloth within 5 mins after delivery or placed skin-to-skin on the breast of the mother. \\
\hline Bathing after $6 \mathrm{~h}$ & Bathing of the baby was delayed until at least $6 \mathrm{~h}$ after the delivery \\
\hline Breast feeding within $1 \mathrm{~h}$ & The mother initiated breastfeeding within the first hour of delivery. \\
\hline No prelacteal feeding & The baby was exclusively fed with breast milk during the first $24 \mathrm{~h}$ of life and not fed any other fluid or prelacteal food. \\
\hline Postnatal care & $\begin{array}{l}\text { The mother and her baby were seen for a postnatal check-up by a health care worker (doctor, nurse or nurse-midwife) } \\
24 \mathrm{~h} \text { after delivery }\end{array}$ \\
\hline
\end{tabular}

conducted per WHO guidance on newborn care and 0 if not, which resulted in a newborn care score ranging from 0 to 9 . All care practices we allocated equal importance so no weights were applied.

\section{Predictors: Literacy and place of delivery}

Literacy and place of delivery were predictors in our analysis. Literacy was defined as the ability to read a short text during the interview and used as indicator of socio-economic status. Place of delivery had three categories: health facility (hospital or health center) or at home with a skilled birth attendant or "SBA" (a doctor, a nurse, a government health worker, or an auxiliary nurse midwife)(home+SBA) or at home without an SBA (home-SBA).

\section{Missing data}

A considerable number of observations had missing values for the practices, due to changes in skip patterns in, and differing versions of, the questionnaires over time. In Nepal (Dhanusha) 53\%, India 17\%, Nepal (Makwanpur) $73 \%$, Bangladesh $30 \%$ of all observations had one or more of the practices missing which meant that the total score was missing as it is a sum of nine newborn care practices. Missing values were higher for hospital deliveries (Nepal (Dhanusha) $88 \%$ of observations had at least one care practice missing, India 46\%, Nepal (Makwanpur) 69\%, Bangladesh 75\%). The care practice with most missing observations was hand washing for Nepal (Dhanusha) (44\%) and Bangladesh (22\%) and clean instrument to cut the cord for India (12\%) and Nepal (Makwanpur) (45\%). Additional file 1 provides a detailed breakdown of the missing values.

Missing data were imputed, replacing missing data with estimated data. This is preferable over analyzing complete cases only, because by removing incomplete cases one loses power and, more importantly, there might be patterns of missingness that would confound results in a complete case analysis. If the available data explains missingness, analysis of imputed data will be less confounded. There should be no systematic explanations for missingness outside the explanatory variables in the imputation model though, otherwise the results will still be confounded. This cannot be formally tested, but one can test the robustness of the results against an analysis of complete cases, which we did.

We used multiple imputation by chained equations (MICE) [14]. Perfect prediction was corrected using an augmented-regression approach [15]. Geographical cluster was included as independent variable in the imputation model to adjust for the clustered sampling design of the demographic surveillance sites. Five imputed datasets were created for estimation of the models.

\section{Statistical analysis}

We analyzed the effect of literacy on the newborn care score in a univariable analysis and the effect of literacy and place of delivery in a multivariable analysis. An interaction term of literacy and place of delivery was included in the second model to study possible differences in the effect of literacy by place of delivery. The analyses were done using a random effect models to adjust for clustering.

Analyses were done using STATA, version 13.

\section{Ethical approval}

All trials that provided underlying data for this study were approved by the ethics committee of the Institute of Child Health and Great Ormond Street Hospital for Children (UK) and by the following research ethics committees: the ethical review committee of the Diabetic Association of Bangladesh; an independent ethics committee in Jamshedpur, India (Eastern India trial); the Nepal Health Research Council (Dhanusha and Makwanpur, Nepal). All trials were conducted in disadvantaged areas with high levels of female illiteracy; all participants gave consent in writing, by thumbprint or verbally. 


\section{Results}

Most women in the Nepal and India sites were illiterate (over two-thirds), compared with only one third of women in the Bangladesh site (Table 3). A minority of women in all sites delivered in a facility ( $2 \%$ of women in Nepal (Makwanpur); around 20\% in the other sites). Skilled birth attendance during a home delivery was rare (0 to3\%). Uptake of facility delivery was substantially higher among literate women than among illiterate women.

Uptake of newborn care practices varied strongly between individual practices (e.g. postnatal care was rare, while not giving prelacteal foods was fairly common in all sites), but was far from universal for most practices (Table 4). Uptake also varied strongly between sites. While for most (86\%) deliveries in Bangladesh at least four newborn practices were done; this was the case for less than half (46\%) of deliveries in Nepal (Dhanusha) (Fig. 1).

Infants of literate mothers were more likely to receive the newborn care practices than infants of illiterate mothers, with a few exceptions (e.g. no prelacteal feeding) (Table 4). A large gap in newborn care practices was observed between illiterate women delivering at home without a SBA and literate women delivering in a facility. In a given place of birth, socioeconomic inequalities in newborn care were, in absolute terms, usually fairly modest (Table 5).

Socioeconomic inequalities in newborn care were also reflected in the higher newborn care score for deliveries among literate mothers compared with illiterate mothers (difference in newborn care score ranging from 0.35 $(0.31,0.39)$ in Bangladesh to $0.80(0.73,0.87)$ in Nepal
(Dhanusha) on a scale of 0 to 9) (Table 6). These socioeconomic inequalities in the newborn care score, as indicated by the beta, became considerably smaller - now ranging from 0.21 (95\% CI: 0.17-0.25) in Bangladesh to 0.43 (95\% CI: 0.36-0.51) in Nepal (Makwanpur) - in a multivariable analysis that also included place of delivery and an interaction term for place of delivery * literacy. In this analysis, the differences in newborn care between literate and illiterate women were much smaller than differences in the newborn care score between facility deliveries and home deliveries without SBA, which ranged from 1.00 (95\% CI: 0.90-1.11 (Bangladesh) to 2.08 (95\% CI: 1.83-2.32) (Nepal (Makwanpur)) units of the score. Socioeconomic inequalities in newborn care score were usually of similar magnitude at home with or without an SBA and in the facility, as indicated by the small and statistically insignificant interaction terms between literacy and place of delivery in all sites, except Nepal (Makwanpur).

\section{Discussion}

We found that newborn care is better in higher socioeconomic groups than in lower socioeconomic groups in rural areas of Bangladesh, India and Nepal. These inequalities are to a large extent explained by the higher percentage of facility deliveries among literate women compared with illiterate women and better newborn care practices in facilities. Infants of illiterate mothers receive more appropriate care in a facility than infants of literate mothers at home. Nevertheless, inequalities in newborn care also exist in facilities with illiterate mothers receiving poorer care.

Table 3 The distribution of literacy and delivery type in the population of the study sites

\begin{tabular}{|c|c|c|c|c|}
\hline & India & Bangladesh & Nepal (Dhanusha) & Nepal (Makwanpur) \\
\hline Number of deliveries & 8720 & 26,835 & 17,835 & 6688 \\
\hline \multicolumn{5}{|l|}{ Literacy } \\
\hline Illiterate (\%) & $68 \%$ & $34 \%$ & $76 \%$ & $66 \%$ \\
\hline Literate (\%) & $32 \%$ & $66 \%$ & $24 \%$ & $34 \%$ \\
\hline \multicolumn{5}{|l|}{ Place of delivery } \\
\hline Home - SBA (\%) & $78 \%$ & $80 \%$ & $78 \%$ & $97 \%$ \\
\hline Home + SBA (\%) & $3 \%$ & $3 \%$ & $1 \%$ & $0 \%$ \\
\hline Facility (\%) & $19 \%$ & $17 \%$ & $21 \%$ & $2 \%$ \\
\hline \multicolumn{5}{|l|}{ Delivery type by literacy } \\
\hline \multicolumn{5}{|l|}{ Literate } \\
\hline Home - SBA (\%) & $61 \%$ & $76 \%$ & $64 \%$ & $94 \%$ \\
\hline Home + SBA (\%) & $5 \%$ & $3 \%$ & $1 \%$ & $1 \%$ \\
\hline Facility (\%) & $34 \%$ & $21 \%$ & $35 \%$ & $5 \%$ \\
\hline \multicolumn{5}{|l|}{ Illiterate } \\
\hline Home - SBA (\%) & $86 \%$ & $89 \%$ & $83 \%$ & $99 \%$ \\
\hline Home + SBA (\%) & $3 \%$ & $2 \%$ & $1 \%$ & $0 \%$ \\
\hline Facility (\%) & $11 \%$ & $8 \%$ & $16 \%$ & $1 \%$ \\
\hline
\end{tabular}


Table 4 Uptake of each individual newborn care practice for the entire population and by literacy (\%)
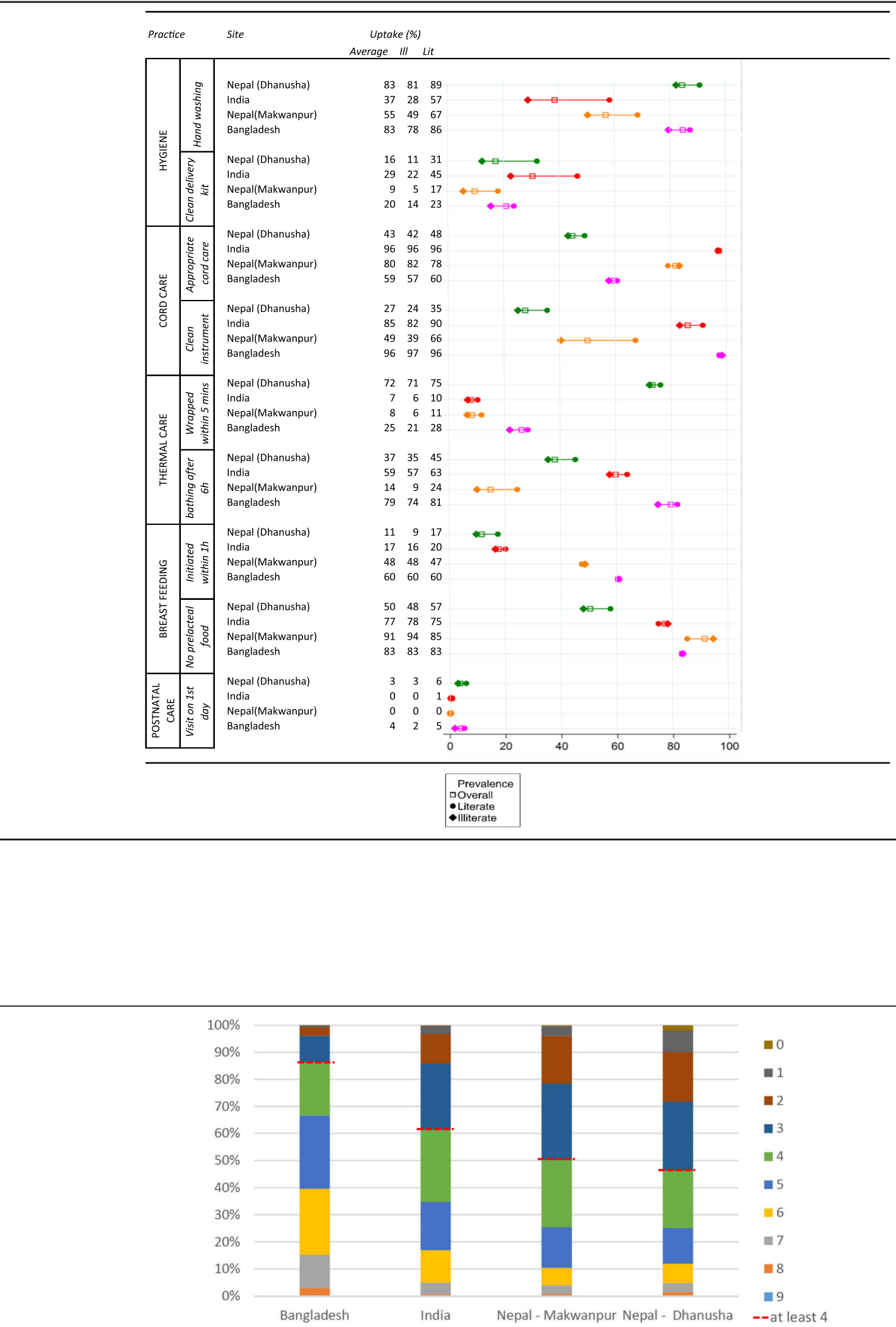

Fig. 1 The proportion of deliveries by number of newborn care practices conducted during the delivery. The red dotted line indicates the proportion of deliveries per site with at least four newborn care practices 
Table 5 Uptake of individual newborn care practices by place of delivery and literacy (\%)

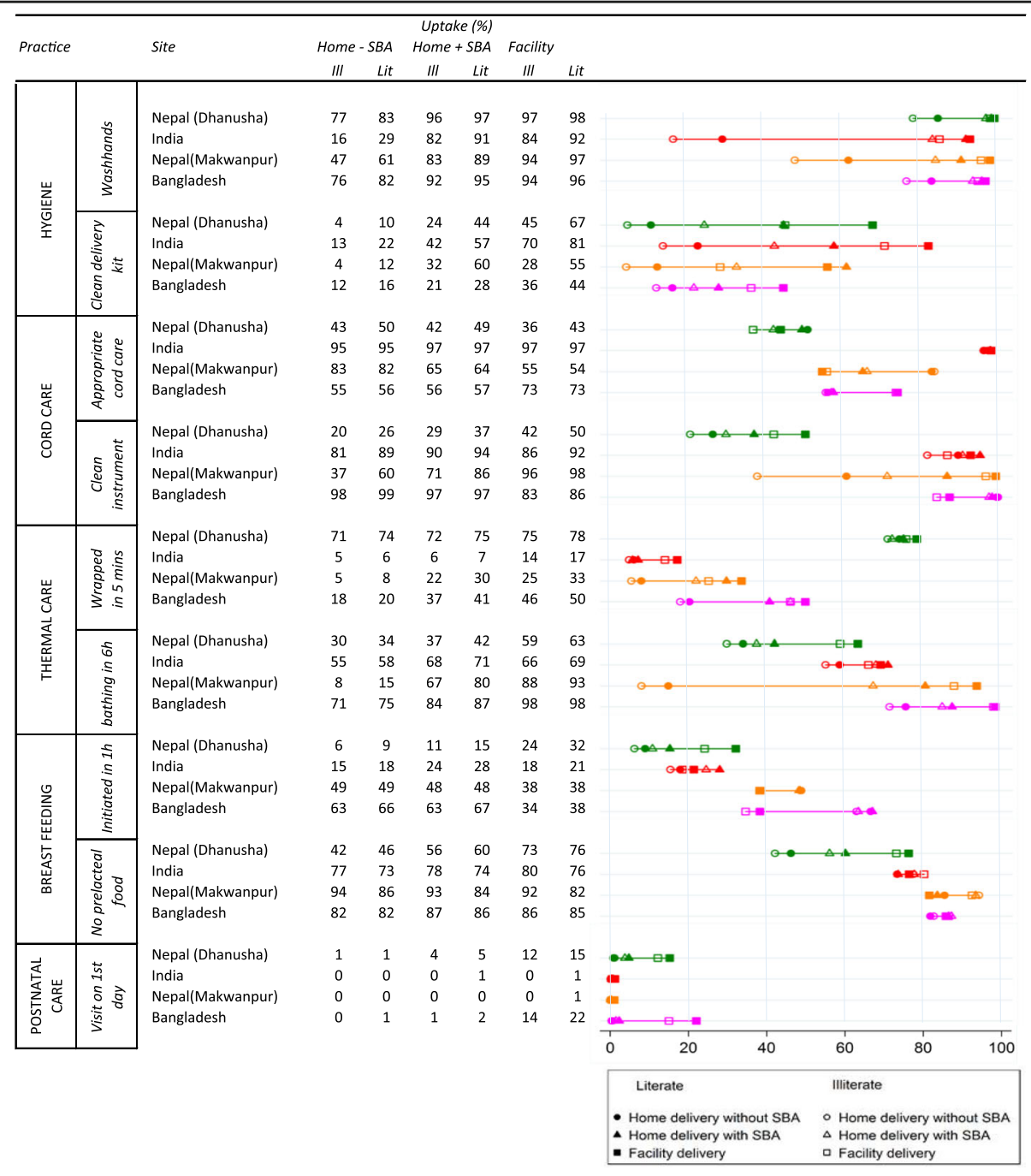

Our study has some limitations. Firstly, a considerable number of observations had missing information on newborn care practices, especially for women delivering in a facility due to a skip pattern in one version of the questionnaire. We solved the missing data problem through imputation. We performed a complete case analysis for comparison with the analysis on the imputed data. The analysis gave comparable results, suggesting that, conditional on the variables included in the imputation model, missingness was at random (Additional file 2).

A second limitation is that the data were collected at least 6 weeks after delivery, which may have resulted in recall bias. However, recall bias in our data is likely to be much lower than in the DHS, which use a recall period of up to 2 years. Finally, the studies were collected over differing time periods (see Table 1), so we do not have concurrent comparisons of the uptake of newborn care practices by site.
A third limitation is that all trials were conducted in disadvantaged areas with high levels of female illiteracy, which should be taken into account when generalizing the results of the analysis to other areas.

In our data we had access to several potential SES indicators: literacy, maternal education and assets. We selected literacy because it is commonly used in health research in developing countries [16-18], it allowed us to categorize low SES in a simple way and was collected consistently across sites. Maternal education in years was available but in different categories across sites. We considered calculating an asset index, which is another indicator often used in health research from developing countries [19]. In our study limited numbers of different assets were collected for the different sites. Generally, calculating asset indices using different sets of assets results in different definitions of low SES [20], so using different sets between sites to calculate the indices in 
Table 6 A model of the effect of literacy on newborn care score (model) and the same model with place of delivery as additional predictor and an interaction term of literacy* place of delivery (model 2)

\begin{tabular}{|c|c|c|c|c|}
\hline & $\begin{array}{l}\text { India } \\
\text { beta }(95 \% \mathrm{Cl})\end{array}$ & $\begin{array}{l}\text { Bangladesh } \\
\text { beta }(95 \% \mathrm{Cl})\end{array}$ & $\begin{array}{l}\text { Nepal (Dhanusha) } \\
\text { beta }(95 \% \mathrm{Cl})\end{array}$ & $\begin{array}{l}\text { Nepal (Makwanpur) } \\
\text { beta }(95 \% \mathrm{Cl})\end{array}$ \\
\hline \multicolumn{5}{|l|}{ Model 1} \\
\hline Illiterate & ref & ref & ref & ref \\
\hline Literate & $0.66(0.59-0.72)$ & $0.35(0.31-0.39)$ & $0.80(0.73-0.87)$ & $0.65(0.57-0.72)$ \\
\hline Constant & $3.85(3.60-4.11)$ & $4.86(4.60-5.12)$ & $3.27(3.13-3.41)$ & $3.37(3.23-3.52)$ \\
\hline \multicolumn{5}{|l|}{ Model 2} \\
\hline Illiterate & ref & ref & ref & ref \\
\hline Literate & $0.28(0.22-0.35)$ & $0.21(0.17-0.25)$ & $0.42(0.35-0.48)$ & $0.43(0.36-0.51)$ \\
\hline Home - SBA & ref & ref & ref & ref \\
\hline Home+SBA & $1.12(0.94-1.30)$ & $0.61(0.46-0.75)$ & $0.83(0.60-1.06)$ & $1.22(0.61-1.82)$ \\
\hline Facility & $1.42(1.32-1.51)$ & $1.00(0.90-1.11)$ & $1.77(1.66-1.87)$ & $2.08(1.83-2.32)$ \\
\hline Home + SBA*literate & $0.15(-0.11-0.41)$ & $0.04(-0.13-0.22)$ & $0.08(-0.29-0.44)$ & $0.69(-0.03-1.41)$ \\
\hline Facility*literate & $0.04(-0.09-0.17)$ & $-0.02(0.14-0.09)$ & $0.11(-0.02-0.25)$ & $-0.33(0.62--0.05)$ \\
\hline Constant & 3.61 (3.39-3.84) & $4.74(4.45-5.04)$ & $2.96(2.82-3.10)$ & $3.30(3.19-3.41)$ \\
\hline
\end{tabular}

our study might have resulted in an inconsistent definition of low SES.

Improving newborn care for every newborn contributes to reducing neonatal mortality, so addressing inequalities in newborn care can arguably contribute to reduced neonatal mortality inequalities [4, 21]. Addressing inequalities in newborn care requires a two-pronged strategy: improving access to good quality facility delivery care, especially for poor women, while at the same time improving practices for home births.

Our findings support the strong push in the international literature promoting facility delivery in low and middle income countries $[4,22]$. The differences in newborn care between facility and home delivery are much larger than between illiterate and literate women. Also among illiterate women, newborn care is much better in the facility than at home. Our analysis only looked at care practices that should happen to every newborn, so the added value of 'higher level' comprehensive emergency obstetric and neonatal care was not taken into account.

Steps have been made in Bangladesh, India and Nepal to increase supply of facility delivery care, although progress is limited by human resources [23, 24]. Large inequalities in uptake of facility delivery, as well as the more general understanding that improved access to medical technology first benefits the better-off, suggest that policies to increase access should include some form of targeting [8, 25]. Demand side strategies, like conditional cash transfer schemes, have been put in place in India, Bangladesh and Nepal, to allow women of lower socioeconomic status to access facility delivery care $[23,24]$. Evidence suggests that these schemes improve access to, and reduce inequalities in, use of facility delivery care, which should improve inequalities in newborn care as well [26].

Inequality in coverage of newborn care practices between literate and illiterate populations delivering in health facilities is a cause for concern. Ideally, once reaching care in a health facility, quality of care should be equivalent for everyone regardless of socioeconomic position. The observed differences can be caused by differences in health facilities with the literate mothers using facilities with a higher standard of care, or due to health workers differentiating their behavior on the basis of the patients' literacy status. Further research is needed to tease this out. Low coverage of some practices even among literate women delivering in in facilities (e.g. postnatal care) is another cause for concern and suggests that there is ample room for improvement in quality of care during facility deliveries.

Efforts to improve quality of home deliveries will also contribute to equity in newborn care. Community-based interventions including community support groups and home visits were associated with increased use of clean delivery kits for home births and early initiation of breastfeeding [27]. Trials in India, Nepal and Bangladesh have demonstrated that participatory learning and action through women's groups can improve newborn care practices in home deliveries across all socioeconomic strata [12, 28, 29]. Given that most deliveries in low- and middle income countries still take place at home, these interventions should be included in national newborn care policies.

In order to ensure that newborn care policies are improving access for the poor, their equity effects must be monitored over time. Crowe, et al. analyzed the same 
demographic surveillance data as we did and showed that the quality of newborn care during attended deliveries reduced over time. For example, rates of hygienic cord-cutting and skin-to-skin contact during attended deliveries fell in Bangladesh over the period 2005-2009, while rates of attended delivery increased [30]. One would be interested to know the equity trend, hypothesizing that the reduced quality of newborn care during facility deliveries would be observed in mainly poor mothers, resulting in bigger inequality in newborn care. Barros et al. developed a framework to monitor equity trends in coverage of maternal, neonatal and child health, but this framework was developed for analyzing DHS datasets and only includes "skilled birth attendance", without looking at individual newborn care practices or distinguishing between place of delivery [31]. We recommend that monitoring equity of newborn care includes place of delivery and that the Demographic Health Surveys should be expanded to include newborn care practices for facility deliveries as well as for home births.

\section{Conclusions}

In summary, socioeconomic status strongly influences newborn care. Within a given place of delivery, socioeconomic status is less important for the newborn care received. Newborn care is much better in health facilities than at home, even for illiterate women, which is an argument for improving access to facility delivery care and improving newborn care practices in the home setting.

\section{Additional files}

Additional file 1: Table S1. Missing data by newborn care practice. Table S2. Missing data by newborn care practice for home deliveries without a skilled birth attendant. Table S3. Missing data by newborn care practice for home deliveries with a skilled birth attendant. Table S4. Missing data by newborn care practice for facility deliveries. (PDF $41 \mathrm{~kb}$ )

Additional file 2: Table S5. Complete case analysis: The distribution (\%) of literacy, delivery type and delivery type by literacy in the population of the study sites. Table S6. Complete case analysis: A univariable model of the effect of literacy on newborn care score. Table S7. Complete case analysis: A multivariable model of the effect of literacy and delivery type on newborn care score including interaction. (PDF $86 \mathrm{~kb}$ )

\section{Acknowledgements}

Not applicable.

\begin{abstract}
Funding
This work was primarily supported by the Economic and Social Research Council and the Department for International Development (grant number ES/1033572/1). Additional support was provided by a Wellcome Trust Strategic Award (award number: 085417MA/Z/08/Z). TAJH was also supported by an EUR Research Excellence Initiative grant. Eric de Jonge was supported by grant from the Rotterdam Global Health Initiative. The funding bodies had no role in the design of the study and collection, analysis, interpretation of data or writing the manuscript.
\end{abstract}

\section{Availability of data and materials}

The data that support the findings of this study are available from the UCL Institute for Global Health and the trial partners but restrictions apply to the availability of these data, which were used under license for the current study, and so are not publicly available. Data are however available from the authors upon reasonable request and with permission of UCL Institute for Global Health and the trial partners.

\section{Authors' contributions}

Tanja AJ Houweling, Kishwar Azad, Dharma S. Manandhar, Prasanta Tripathy, Ellen van de Poel and Anthony Costello obtained funding for the study. Erik de Jonge and TanjaAJ Houweling designed the analysis presented in this paper. Erik de Jonge, Tanja AJ Houweling, Md. Munir Hossen, Abdul Kuddus, Swati Sarbani Roy, Naomi Saville, Aman Sen, and Catherine Sikorski analysed and interpreted the data. Swati Sarbani Roy, Naomi Saville, Aman Sen and Md. Muir Hossen coordinated data collection and management in the field sites. Erik de Jonge prepared the first draft of this manuscript. Tanja AJ Houweling, Kishwar Azad, Dharma S. Manandhar, Prasanta Tripathy, and Anthony Costello supervised the study and its underlying data collection. All authors reviewed, revised and approved the manuscript.

\section{Ethics approval and consent to participate}

All trials that provided underlying data for this study were approved by the ethics committee of the Institute of Child Health and Great Ormond Street Hospital for Children (UK) and by the following research ethics committees: the ethical review committee of the Diabetic Association of Bangladesh; an independent ethics committee in Jamshedpur, India (Eastern India trial); the Nepal Health Research Council (Dhanusha and Makwanpur, Nepal). All trials were conducted in disadvantaged areas with high levels of female illiteracy; all participants gave consent in writing, by thumbprint or verbally.

Consent for publication

Not applicable.

\section{Competing interests}

The authors declare that they have no competing interests.

\section{Publisher's Note}

Springer Nature remains neutral with regard to jurisdictional claims in published maps and institutional affiliations.

\section{Author details}

${ }^{1}$ Department of Public Health, Erasmus University Medical Center, P.O. Box 2040, 3000, CA, Rotterdam, the Netherlands. 'Perinatal Care Project, Diabetic Association of Bangladesh, 122 KaziNazrul Islam Avenue, Dhaka 1000, Bangladesh. ${ }^{3}$ Mother Infant Research Activities (MIRA), YB Bhavan, Thapathali, Kathmandu 921, Nepal. ${ }^{4}$ Ekjut, Plot 556B, Potka, Chakradharpur, West Singhbhum, Jharkhand, India. ${ }^{5}$ Institute of Health Policy and Management, Erasmus University Rotterdam, Rotterdam, the Netherlands. ${ }^{6}$ Institute for Global Health, University College London, London, UK.

Received: 30 January 2018 Accepted: 1 August 2018

Published online: 15 August 2018

\section{References}

1. Lawn JE, Cousens S, Zupan J. Lancet Neonatal Survival Steering Team.4 million neonatal deaths: when? Where? Why? Lancet. 2005;365(9462):891-900.

2. McKinnon B, Harper S, Kaufman JS, Bergevin Y. Socioeconomic inequality in neonatal mortality in countries of low and middle income: a multicountry analysis. Lancet Glob Health. 2014;2(3):e165-73.

3. Darmstadt GL, Bhutta ZA, Cousens S, Adam T, Walker N, de Bernis L, Lancet Neonatal Survival Steering Team. Evidence-based, cost-effective interventions: how many newborn babies can we save? Lancet. 2005;365(9463):977-88.

4. Bhutta ZA, Das JK, Bahl R, Lawn JE, Salam RA, Paul VK, Sankar MJ, Blencowe $\mathrm{H}$, et al. Lancet Every Newborn Study Group. Can available interventions end preventable deaths in mothers, newborn babies, and stillbirths, and at what cost? Lancet. 2014;384(9940):347-70.

5. Countdown 2008 Equity Analysis Group, Boerma JT, Bryce J, Kinfu Y, Axelson H, Victora CG. Mind the gap: equity and trends in coverage of maternal, newborn, and child health services in 54 Countdown countries. Lancet. 2008;371(9620):1259-67.

6. Victora CG, Requejo JH, Barros AJ, Berman P, Bhutta Z, Boerma T, Chopra M, de Francisco A, et al. Countdown to 2015: a decade of tracking progress for maternal, newborn, and child survival. Lancet. 2016 May 14;387(10032):2049-59. 
7. Pagel C, Prost A, Hossen M, Azad K, Kuddus A, Roy SS, Nair N, Tripathy P, et al. Is essential newborn care provided by institutions and after home births? Analysis of prospective data from community trials in South Asia. BMC Pregnancy Childbirth. 2014;14:99.

8. Houweling TA, Ronsmans C, Campbell OM, Kunst AE. Huge poor-rich inequalities in maternity care: an international comparative study of maternity and child care in developing countries. Bull World Health Organ. 2007;85(10):745-54.

9. Hancioglu A, Arnold F. Measuring coverage in MNCH: tracking progress in health for women and children using DHS and MICS household surveys. PLoS Med. 2013;10(5):e1001391.

10. Ministry of Health and Population (MOHP) [Nepal], New ERA, and ICF International Inc. Nepal Demographic and Health Survey 2011. Kathmandu, Nepal: Ministry of Health and Population, New ERA, and ICF International, Calverton, Maryland; 2012.

11. National Institute of Population Research and Training (NIPORT), Mitra and Associates, and ICF International. Bangladesh Demographic and Health Survey 2011. Dhaka, Bangladesh and Calverton, Maryland, USA: NIPORT, Mitra and Associates, and ICF International; 2013.

12. Prost A, Colbourn T, Seward N, Azad K, Coomarasamy A, Copas A,

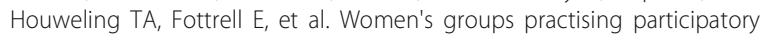
learning and action to improve maternal and newborn health in lowresource place of delivery: a systematic review and meta-analysis. Lancet. 2013;381(9879):1736-46.

13. WHO: Pregnancy, Childbirth, Postpartum and Newborn Care: a guide for essential practice; 2006.

14. White IR, Royston P, Wood AM. Multiple imputation using chained equations: Issues and guidance for practice. Stat Med. 2011;30(4):377-99.

15. White IR, Daniel R, Royston P. Avoiding bias due to perfect prediction in multiple imputation of incomplete categorical variables. Comput Stat Data Anal. 2010;54(10):2267-75.

16. Bicego GT, Boerma JT. Maternal education and child survival: a comparative study of survey data from 17 countries. Soc Sci Med. 1993;36(9):1207-27.

17. Cleland JG, van Ginneken JK. Maternal education and child survival in developing countries: The search for pathways of influence. Social Science \& Medicine. 1988;27(12):1357-66.

18. Cortinovis I, Vella V, Ndiku J. Construction of a socio-economic index to facilitate analysis of health data in developing countries. Soc Sci Med. 1993 Apr;36(8):1087-97

19. Filmer D, Pritchett LH. Estimating wealth effects without expenditure data--or tears: an application to educational enrollments in states of India. Demography. 2001 Feb;38(1):115-32.

20. Houweling TA, Kunst AE, Mackenbach JP. Measuring health inequality among children in developing countries: does the choice of the indicator of economic status matter? Int J Equity Health. 2003;2(1):8.

21. Seward N, Osrin D, Li L, Costello A, Pulkki-Brännström AM, Houweling TA, et al. Association between clean delivery kit use, clean delivery practices, and neonatal survival: pooled analysis of data from three sites in South Asia. PLoS Med. 2012 Feb;9(2):e1001180.

22. Filippi V, Ronsmans C, Campbell OM, Graham WJ, Mills A, Borghi J, Koblinsky M, Osrin D. Maternal health in poor countries: the broader context and a call for action. Lancet. 2006:368(9546):1535-41.

23. Pradhan W, Upreti SR, Pratap KC, Khadka N, Syed U, Kinney MV, Adhikari RK, Shrestha PR, et al. Newborn survival in Nepal: a decade of change and future implications. Health Policy Plan. 2012;27(Suppl 3):iii57-71.

24. Rubayet S, Shahidullah M, Hossain A, Corbett E, Moran AC, Mannan I, Matin Z, Wall SN, et al. Health Policy Plan. 2012;27(Suppl 3):iii40-56.

25. Hart JT. The inverse care law. Lancet. 1971;1(7696):405-12.

26. Ahmed S, Khan MM. Is demand-side financing equity enhancing? Lessons from a maternal health voucher scheme in Bangladesh. Soc Sci Med. 2011;72(10):1704-10.

27. Lassi ZS, Bhutta ZA. Community-based intervention packages for reducing maternal and neonatal morbidity and mortality and improving neonatal outcomes. Cochrane Database Syst Rev. 2015;3:CD007754.

28. Houweling TA, Looman CW, Azad K, Das S, King C, Kuddus A, et al. The equity impact of community women's groups to reduce neonatal mortality: a meta-analysis of four cluster randomized trials. Int J Epidemiol. 2017. https://doi.org/10.1093/ije/dyx160.

29. Houweling TA, Tripathy $P$, Nair N, et al. The equity impact of participatory women's groups to reduce neonatal mortality in India: secondary analysis of a cluster-randomised trial. Int J Epidemiol. 2013;42(2):520-32.
30. Crowe S, Prost A, Hossen M, Azad K, Kuddus A, Roy S, et al. Generating Insights from Trends in Newborn Care Practices from Prospective Population-Based Studies: Examples from India, Bangladesh and Nepal. PLoS One. 2015:10(7):e0127893.

31. Barros AJ, Victora CG. Measuring coverage in $\mathrm{MNCH}$ : determining and interpreting inequalities in coverage of maternal, newborn, and child health interventions. PLoS Med. 2013;10(5):e1001390.
Ready to submit your research? Choose BMC and benefit from:

- fast, convenient online submission

- thorough peer review by experienced researchers in your field

- rapid publication on acceptance

- support for research data, including large and complex data types

- gold Open Access which fosters wider collaboration and increased citations

- maximum visibility for your research: over $100 \mathrm{M}$ website views per year

At $\mathrm{BMC}$, research is always in progress.

Learn more biomedcentral.com/submissions 